\title{
Boredom and its typologies
}

\section{KEYWORDS}

boredom, typologies of boredom

\begin{abstract}
Chruszczewski Michał H., Boredom and its typologies. Culture - Society - Education no. 1(17) 2020, Poznań 2020, pp. 235-249, Adam Mickiewicz University Press. ISSN 2300-0422. DOI 10.14746/kse.2020.17.10.2

Boredom is a very interesting issue that persists in our contemporary day and age. It is not easy to define it in a positive sense (by listing its properties, which constitute a presence of something, rather than a lack of something), as it has vastly differentiated causes and symptoms. The paper presents a variety of types of boredom identified from various points of view in the humanities and social sciences. According to the author, two of these typologies are particularly convincing. The first introduces the division into the state and a trait of boredom, while the latter describing only the state of boredom in terms of arousal and affect - postulates the existence of neutral, calibrating, searching, reactant and apathetic boredom. These typologies have been juxtaposed with others, with their similarities and differences identified and indicated.
\end{abstract}

What is boredom? "The idleness of the mind which knows not what to do" as Ignacy Krasicki wrote in his Pan Podstoli (1994: 131)? "The fruit of glum indifference" as Charles Baudelaire (1991: 199) put it in one of his four Spleen poems? Or perhaps the result of an internal conflict, an impairment of vitality or the effect of monotonous work as the first researchers of this phenomenon claimed? ${ }^{1}$

* ORCID https://orcid.org/0000-0002-3584-8680.

1 That is Émile Tardieu (1904), Hudson A. Davies (1926) and Joseph Barmack (1939). 


\section{Boredom, its essence and definitions}

The answer to the question about the nature of boredom, a phenomenon that is quite common, often commonly considered trivial, is surprisingly complex in light of the findings of contemporary science. This was already an issue noted in the past by philosophers, who wrote about the indefiniteness of boredom (de Jaucourt, 1755, after: Markowski, 1999a: 292) or by defining it tautologically (Kierkegaard, 1976: 39). Nowadays, we draw attention to components or determinants of boredom such as low agitation, unpleasantness, subjective repetitiveness, sense of acting in conditions of limitations (Geiwitz, 1966: 594), lack of internal motivation and lack of challenges (Csikszentmihalyi, 1975: 49), negative mood related to lack of action and sense of emptiness (Gurycka, 1977). The environmental conditions of boredom, such as non-stimulating environment, ${ }^{2}$ were emphasised by William L. Mikulas and Stephen J. Vodanovich (1993: 3). Robert Plutchik (1980: 158) defined boredom as a mild form of disgust. James A. Russell (1980: 1167) considered it to be a conjunction of a mildly intense negative affect and negligible agitation. In turn, Anna B. Hill and Robert E. Perkins (1985: 236) believed boredom to be the fruit of a different conjunction: subjectively experienced monotony and frustration of needs. According to researchers oriented towards cognitive sciences, the inability to maintain attention is a key feature of boredom (Cheyne, Carriere, Smilek, 2006: 580). Lack of interest combined with motivation to avoid what caused boredom was mentioned by scholars such as Reinhard Pekrun, Thomas Goetz, Lia M. Daniels, Robert H. Stupnisky and Raymond P. Perry (2010: 533). Carlo Maggini (2005) noted the variability of stimulation in boredom (decreased cortical stimulation, increased stimulation of the sympathetic trunk of the autonomic nervous system), worsening of attention, increased tendency to seek sensations and stressed the importance of the cerebral reward system. Colleen Merrifield (2014: 30) also wrote about the worsening of attention in boredom combined with experienced stress. In the context of a lack of sense of meaning, boredom was described by many scholars - Lars Svendsen (2005: 30) from the philosophical standpoint, Krzysztof J. Szmidt (2013: 59) from the teaching standpoint, Wijnand A. van Tilburg and Eric R. Igou (2012: 182) from the psychological standpoint, and Barbara A. Misztal (2016: 112) took it on from sociological perspective. What is interesting is the fact that boredom is more often put in negative categories lack of engagement, lack of meaning, lack of stimulation, rather than in positive

\footnotetext{
2 This was pointed out in the 18th century by encyclopaedist Elisabeth de Jaucourt, see: Markowski, 1999a.
} 
categories, with some attributes. This shows the difficulty of capturing its essence. Hence Elisabeth S. Goodstein (2005) in the title of her book referred to boredom as "Experience Without Qualities".

\section{Causes and symptoms of boredom}

Boredom usually comes from understimulation; however, it may also manifest itself in reactions that indicate both a state of low cortical excitation and high excitation in the autonomic nervous system. There are biological bases of boredom (including genetic and biochemical), but its psychological and phenomenological symptoms are equally as important. Boredom is a great motivating force to change one's position or come up with creative solutions, but if such a change fails or proves to be impossible, then depressive reactions are likely to occur. This applies to both humans and many evolutionally advanced animals. Individual proneness to boredom increases the chance of experiencing a state of boredom. In school conditions, as well as in professional work, boredom is systematically linked to the other properties of the subject and the environment, often leading to a deterioration in functioning and mental well-being.

Attempts to synthesize knowledge about boredom are offered by Shelley A. Fahlman (2008, see also: Fahlman, Mercer-Lynn, Flora and Eastwood, 2013), Patricia L. Baratta and Jeffrey R. Spence (2018) and Andreas Elpidorou (2018). The first two proposals are based on the results of advanced statistical analyses carried out in connection with the creation of questionnaires for measuring boredom. Elpidorou, on the other hand, has made a more rational, rather than empirical (although ultimately based on study results) elaboration on the state of knowledge about boredom. The least complex picture of boredom is drawn by Baratta and Spence: in their opinion, boredom is a system of negative arousal with little power, carelessness and lack of engagement. According to Fahlman and her associates, boredom is a property that is made up of five positively correlated components: lack of engagement, lack of attention, perception of the passage of time (perceived as long and stalled), high stimulation (irritation, nervousness) and low stimulation (depression). According to Elpidorou, the state of boredom includes dissatisfaction with the status quo; withdrawal of one's own involvement in one's surroundings; feeling of limitation imposed on the subject's activity; problems with focus; usually low, but sometimes high stimulation; change in the way one perceives time; a deficit of meaning and a feeling that the requirements of the situation in which one finds themselves are inadequate (too high or too low); specific bodily-motor expression (such as inclination of the trunk,

resting one's head on one's hand, low spatial expansion and poor dynamics of move- 
ment); psychophysiological background (including specific activity of the dorsal/ lateral prefrontal cortex). Apart from the state of boredom described above, there is also boredom understood as a relatively permanent disposition that increases the probability of experiencing the states of boredom in life (see for example Farmer and Sundberg, 1986: 14).

\section{Typological classifications of boredom}

An interesting and original theoretical approach to the phenomenon of boredom is the typological approach. By postulating the existence of separate, peculiar and relatively stable ways of being bored, the typologies of boredom try to capture and consolidate the qualitative differences in the experience of boredom - an experience that is supposedly without qualities. Thus, they significantly deepen our knowledge of this experience or phenomenon. There are many typologies of boredom. One might even say that their diversity reflects, to some extent, the diversity of the approaches to its definition. Discussion of the typology of boredom is the main aim of this paper.

The known typologies of boredom are characterised by a range of two to five categories of boredom specified by them. Some typologies are based on observation and rational thinking, others are based on empirical studies and statistical analysis of data. There were also some humorous proposals, located on the borderline of philosophy and fiction. All typologies bring something new, though not to the same extent. It is worth noting that - as though in contrast to typology - there is also the idea of boredom being uniform, indivisible. In particular, Wendell O'Brien (2014: 243) proclaimed this idea arguing on the basis of philosophical analysis supported by a declaration of personal disbelief in existential boredom. He was of the opinion that in one more general idea of boredom it is possible to find all types distinguished by other theorists, constituting different manifestations of the same category. Most often, however, two kinds of boredom were brought up. Let us then take a closer look at the dual typologies.

Psychoanalyst Ralph Greenson (1953: 18) distinguished two types of boredom: apathetic, which is brought about by blocking the drive and instrumental goals, and agitated, that is brought about by experiencing failures and frustration. Boredom is a state of a withdrawal of the driving force from the outside world (Greenson, 1949: 299). This is consistent with what is nowadays called the withdrawal of environmental engagement. Jerome Neu (1998: 163) distinguished endogenous boredom, with intra-personal causes, independent of the environment, from exogenous (reactive), environmental boredom, caused by the situation. This 
is somewhat similar to depression with internal causes or causes stemming from the living environment. Neu stated that Greenson omitted reactive boredom due to the fact that he focused on chronic boredom, potentially psychopathological, and the personality traits that could predispose the individual to said boredom.

A well-known phenomenon in psychology is the dualism of trait and state. This applies, for example, to anxiety, social approval, but also to boredom. Boredom as a state would correspond to exogenous boredom, while boredom as a trait would correspond to endogenous boredom. In the detailed depiction of boredomas-a-trait, significant differences of approached adopted by individual researchers become apparent. According to Marvin Zuckerman (Zuckerman, Eysenck and Eysenck, 1978: 140) people sensitive to boredom look for sensations at any cost, while according to Richard F. Farmer and Norman D. Sundberg (1986: 11) people susceptible to boredom tend to be sad, depressed, worried, rather than impulsively looking for adventures in the name of fighting boredom. In other words, Farmer and Sundberg outline boredom more comprehensively than Zuckerman. They see boredom as something more than a hunger for experiences stemming from understimulation. The statistical reflection of the differences in content between vulnerability to boredom and proneness to boredom is a weak correlation: $r=0.25$ of the relevant scales (Zuckerman's ZBS and Farmer and Sundberg's BPS) measuring the two properties. This proves a lack of convergent accuracy and makes one think about differences in the theoretical basis of both correlated variables (Farmer and Sundberg, 1986: 10). There is also talk of long-lasting and temporary boredom (see for example: Winter, 2012: 33) as well as boredom that is situational and independent of the situation (Todman, 2003: 147, cf: Flakus and Palt, 2016: 121). Endogenous boredom, which is a permanent trait of an individual, which means that it is independent of the situation, is associated with the notion of boredom-as-a-trait and may exhibit links with mental disorders, while reactive, temporary boredom - dependent on the situation is considered to be something ordinary, not interpreted clinically and is associated with the notion of boredom-as-a-state. Similarly, Otto Fenichel (1951: 359) distinguished pathological boredom from normal (non-pathological) boredom, while Tadeusz Gadacz (2002) contrasted existential boredom with idleness. Magdalena Bizior-Dombrowska (2016: 82-83) recalls the distinction made by Gustave Flaubert between common boredom and modern boredom (see: Flaubert, 1881/1955; cf.: Svendsen, 2005: 42). Common boredom is reactive, situational and so on, modern boredom resembles the endogenous and even existential one. Most probably, however, not every long-term (modern) boredom reaches the depth - or rather the emptiness - of existential boredom. The latter would be an unusually intense case of long-term boredom, independent of the situation, endogenous, characterised by ex- 
periencing nothingness and loss of meaning as well as a total lack of satisfaction with one's own life. In addition, existential boredom is a specifically European cultural construct. ${ }^{3}$ As such, it reinforces my objection.

Almost all the dual typologies of boredom presented thus far were variations on the same subject. The exception is the division presented by Greenson, in two heterogeneous forms (which can go from one form to the other in the course of boredom): apathetic boredom and agitated boredom, which are covered by the superior type of boredom-as-a-trait (pathological boredom). An interesting coincidence is that statistical studies of the internal structure of proneness to boredom understood according to Farmer and Sundberg's concept have resulted in two factors: external and internal stimulation. The former is expressed in the (frustrated in the state of boredom) need for diversity and variety, and also in the perception of the environment as hardly stimulating. The latter is defined by the inability to provide sufficient stimulation, inability to find or create an interesting activity. The external stimulation factor is similar to boredom with irritation, while the internal stimulation factor is related to apathetic boredom.

A radically different division of boredom was introduced by Bertrand Russell (1970) writing about stupefying boredom and fruitful boredom. The lack of life activity leads to stupefying boredom, while avoiding medication (especially being free from abuse) is supposed to lead to fruitful boredom. The author believed that life devoid of impressions and experiences is boring in a stupefying way; on the other hand, life filled with excitement requires more and more powerful stimuli, which is ultimately exhausting. In other words, those who are not stuck in apathy, but who are not dependent on the next dose of stimulants, can get bored while avoiding overstimulation. In their boredom they sometimes come to interesting conclusions or intriguing ideas. This is the author's explanation of the idea of fruitful boredom. Moreover, the creative process according to B. Russell requires that the creator first experiences peace, repetition and boredom. ${ }^{4}$

${ }^{3}$ Intercultural research on boredom in general is sparse (Ng, Liu, Chen and Eastwood, 2015; with regard to the structure of time: Vodanovich and Watt, 1999). The already classic work by Sundberg, Latkin, Farmer and Saund (1991), which analysed the results of the BPS boredom proneness questionnaire filled in by students from Australia, Hong Kong, Lebanon and the United States, is even more important. The highest degree of proneness to boredom was found in the Lebanese. The Lebanese arm of the study was carried out in 1983, during the civil war. At that time, the study probably diagnosed boredom of deprivation and alienation, withdrawal from a more active life as a defensive response to many extremely bad life experiences. This is more or less how the authors of the study interpreted their own results.

${ }^{4}$ In the 16th century, de Michel Montaigne recognised inactivity as a catalyst of intellectual productivity, which frankly surprised him. This was expressed in the eighth chapter of the first volume of his Essays (Montaigne, 1580/2009, vol. 1, p. 94), saying: "a bored mind is always moving from one thought to another." 
Seán D. Healy described three types of boredom in his book (1984). The first one is everyday situational boredom, associated with monotony. The second is overwhelming boredom as a constant characteristic, disposition, resembling the Romantic l'ennui. But the worst of them is hyperboredom or l'ennui moderne. In this state, the individual perceives the world as insufficient, as if thwarting existence. The content of hyperboredom is the experience of helplessness and loneliness, the collapse of ambitions, plans and aspirations, and therefore the overwhelming nothingness - the feeling of being unable to set any goal in life. This goal would be without any chance of success, but what is more important is that in the state of hyperboredom, the world offers nothing that would be worth the effort. According to Healy, the third kind of boredom is not so much about individual pathology as about cultural one. The cause of hyperboredom is the disintegration of culture (civilisation), which - in a historical process stretching over several centuries - finally ceased to provide people with an understandable and meaningful reference system for their actions. This is due to the twilight of the idea of God as the guarantor of order, disbelief in the possibility of transcendence, disintegration of the concepts of truth and subject (which lasted for a long time, but was accelerated by postmodern discourse). As a result, we witness the collapse of authorities, the disappearance of historical memory, radical scepticism and nihilism. According to the author, this is the breeding ground for fear, alienation, violence, vandalism, addictions. The structure of the "self" is a product of culture, and therefore the dissociation of culture must reflect the dissociation of the "self" (Healy, 1984). One could risk claiming that hyperboredom is not far from anomie.

Another division of boredom was presented by Milan Kundera (1997/2001) in the sixth chapter of his Identity. During a walk along the seashore, the book's protagonist remembered his own private theory of passive (situational), active and rebellious boredom. Generally speaking, boredom appears at the junction of existence and time (which, by the way, is somewhat Heideggerian). A girl waiting at a stop near the beach, who mechanically dances alone and yawns, personifies passive boredom. Active boredom is practised by men playing with kites. They are giving in to an unproductive hobby. The young people involved in vandalism (setting fire to cars, breaking shop windows) personify the notion of rebellious boredom. The author believes that active boredom is tantamount to spending time in a socially acceptable way, while rebellious boredom refers to the same, but in an unacceptable way. According to Bizior-Dombrowska (2016: 85-86), the typology proposed by Kundera is one of the most peculiar in literature; the scholar also considered multiple references to Jean-Paul Sartre's Nausea in Kundera's Identity 
(for example, the maritime landscape). On the other hand, Svendsen (2005: 41) did not find any revealing qualities in Kundera's distinctions - he considered them to bring nothing new, except for the fact that boredom can be dealt with actively or passively. According to Svendsen, the division proposed by the author of Identity does not qualitatively capture different forms of boredom, so he rejected it in favour of Doehlemann's four-category typology.

Sociologist Martin Doehlemann (1991, after: Svendsen, 2005: 41-42) proposes distinguishing situational boredom, boredom stemming from excess, existential boredom and creative boredom. The paper has already outlined the situational and existential boredom. The excess of content of a specific type or repetition of the same experience results (probably due to an unjustified generalisation) in boredom stemming from excess. It makes one feel like everything is trivial, devoid of much meaning. Creative boredom is distinguished by its result, not its content: the creation of a creative idea or work. Thus, boredom is creative, as long as it effectively induces a bored person to do something new and valuable.

Boredom in the professional context was dealt with by Fred Mael and Steve Jex (2015), organisation and work psychologists. They found the existence of episodic boredom, which stands in opposition to chronic boredom, as well as situational and global boredom. These binary divisions overlap, thus Mael and Jex (2015: 137) posit that there are four types of boredom: episodic situational, chronic situational, episodic global and chronic global. A factor causing episodic situational boredom may be an event (for example, meeting someone and having an uninteresting conversation), an activity (a specific, unattractive task to perform) or psycho-physiological changes in the body (resulting in mood swings). This kind of boredom is evanescent. Situational chronic boredom extends over certain areas of life, being their permanent fixture (it happens for example when a person is completely bored with their professional work, but not bored with private life). At the same time, experiencing boredom in all areas of our lives, but fortunately for a short time would amount to global episodic boredom. However, such sensation would be more likely to be experienced by people with a higher individual proneness to boredom (which is due to individual differences, for example in terms of temperament and personality traits). The last category is chronic global boredom, most damaging and dangerous. It is a boredom that has seized all areas of life in a lasting way. It is often accompanied by depression, loneliness, resignation, a sense of defeat - which is sometimes apt. According to Mael and Jex, the fourth and worst type of boredom is increasingly affecting humanity in modern times. This is due, among other things, to the economic processes which have been forcing many people to work below their 
qualifications, because there are no other jobs for them, since at least mid-1990s (Mael and Jex, 2015: 152). In this context, the authors also point to the telecommunications revolution (Internet, innovative mobile phones, other devices) and the information overload it has brought. Since people began to suffer from attention deficit disruptions on a massive scale, they have been more likely to get bored (by not being able to keep focused).

The existence of four completely different types of boredom was postulated by Michał P. Markowski (1999b), a Polish scholar and literary theoretician with philosophical interests, distinguishing metaphysical and social boredom, boredom stemming from loneliness, as well as communication and literary boredom. The author claims that in his typology he reveals types of boredom already existing at the end of the 18th century. By metaphysical boredom he means a world without God or filled only with human desires. Metaphysical boredom is the emptiness, desolation, moral and spiritual fall from which the humanity cannot rise alone (that is, without trusting God). That is also what Blaise Pascal postulated back in his day. In turn social boredom is a world without solitude or with the same people all the time. It is like a salon boredom, a nightmare of an eternity of empty and idle conversations. The boredom of an infinite afternoon at the Duchess, but unfortunately one that lacks the qualities of Oriana de Guermentes (and no one like Baron de Charlus came... thus, there are no attractions whatsoever, meaning that all that remains is the habitual talking for passer le temps). The boredom stemming from loneliness is, by contrast, a world without the Other, without a chance for an authentic encounter. The lack of another human being makes it impossible to introduce diversity into one's own existence, which means being in an extremely unpleasant state of loneliness. It is apparent that in the emptiness it is impossible to establish any human relationship. In social boredom there were people, but there was no authentic relationship; in boredom stemming from loneliness, there are no people, so there is no space for any bond between them. The most original type, the communication and literary boredom thickens over a world without fiction or under the boot of tyranny of a single narrative. Lack of narration (fiction) leads to boredom, because people have been telling themselves stories for millennia to avoid boredom (among other things). In turn, a single total narrative, the entirety that monopolises the individual parts, the negation of emancipation (and the nightmare of postmodernists), leads to boredom due to its invariability, exclusivity, thus repetitiveness, and finally - predictability. Sooner or later this kind of story will get boring.

The five-category typology of boredom proposed by Goetz et al. (2014) is distinguished from the others by a very careful empirical foundation and the use of 
advanced techniques of statistical data analysis. Initially Goetz and Anne C. Frenzel (2006, after: Goetz et al., 2014: 403) distinguished four types of boredom, but later decided to add the fifth type (Goetz et al., 2014: 408). Depending on external circumstances, boredom of one type may turn into boredom of another type, so it is easy to find different types of boredom in every person's experience, but often one of them is experienced clearly more often becoming a kind of individual dominant. There is probably an individual, probably partially stemming from one's personality, tendency to get bored in a specific way. In general, both variable environmental factors and relatively constant individual factors influence the frequency and manner of one's boredom. The authors' study involved secondary school students and university students. Their task was to imagine someone who was bored and describe their mood, as well as to recall a boring class or lecture. Then the respondents answered questions about what they had in mind when they were bored, what they would like to do and what somatic experiences they had then. Thus, the questions asked about the cognitive, motivational and physiological aspect of boredom. J. Russell's two-dimensional mood model (1980: 1163-1164) using the concepts of arousal power and pleasure was selected as the theoretical reference system organising the various and not always compatible accounts of the study participants. The condition identified by the researchers, which was characterised by low agitation and slightly positive affect was referred to as indifferent boredom. This feeling resembles a state of relaxation or happy fatigue with a touch of withdrawal. Let us recall that in the state of boredom the activity of $\beta$-waves, related to focus is lowered, while the activity of $\alpha$-waves, related to relaxation, may be going up. The state with a higher but still low agitation, yet slightly negative affect is supposed to correspond to calibrating boredom. This type of boredom leads to being lost in thoughts, yet people who experience it do not know exactly what they would like to do - they only know that they want to do something else. Thus, it is characterised by a mental readiness to change the situation (to a less boring one), but without making real efforts to do so. Much higher agitation and a more negative affect describe searching boredom, which is significantly unpleasant, characterised by nervousness and active searching for a more attractive activity. The highest level of agitation combined with a very negative affect determine reactant boredom. In this state, we can see anxiety, aggression, persistent thinking about much nicer activities or situations. Reactant boredom is very unpleasant and gives rise to a strong tendency to avoid it by changing the situation to another one and avoiding specific people, who people associate with getting them into this state (for example teachers or lecturers). The fifth type of boredom, identified after 
years of further research by the scholars, based on the analysis of latent profiles ${ }^{5}$ is apathetic boredom. It is characterised by the strongest negative affect (even greater than in reactant boredom) and at the same time very low agitation. The results of study by Goetz et al. (2014: 411) involving students showed that the highest level of anger and anxiety and the lowest level of mental well-being and satisfaction with one's life was found in people who primarily experienced reactant boredom. The most positive profile of results in terms of quality of life measures was recorded in school and university students experiencing mainly indifferent boredom. On the other hand, the dominance of apathetic boredom in the whole experience of boredom was associated with relatively low rates of positive emotions, anger and anxiety. According to the authors, apathetic boredom is associated primarily with sadness, learned helplessness and depression. The empirically demonstrated qualitative differences in boredom, together with the classification of types of boredom, based on a generally recognised theoretical model of mood, is one of the most important among the latest achievements in boredom research.

\section{Typologies of boredom in comparative terms}

A comparative analysis of these typologies of boredom, according to which there are three or four types of boredom, should be carried out while taking into account the knowledge of binary typologies. This, however, poses a number of difficulties. This is largely because these typologies come from different fields. Kundera's typology is fiction and the main purpose of the book was hardly to provide scientific insights into boredom. Healy's and Markowski's concepts, which belong to the humanities, owe a lot to historical, literary and philosophical studies. Doehlemann's typology is a manifestation of sociological thought, while Mael's and Jex's typology was developed in the field of psychology. What is the most apparent is the fact that theoreticians recognise situational boredom the list includes Healy, Doehlemann, Mael and Jex, as well as Kundera (who referred to it as passive boredom). Markowski's social boredom resembles a specific (social) kind of situational boredom, but with an extreme intensity (Mael and Jex would refer to it as chronic situational boredom). It seems to me that it is also

\footnotetext{
${ }^{5}$ Latent profile analysis is a variation of latent class analysis. The method has the same purpose as cluster analysis (however, it is more difficult), namely to divide the group of objects (or people in this case) into groups so that the objects assigned to each group are as similar to each other as possible (here: in terms of the way of experiencing boredom estimated on the basis of two dimensions of mood), and at the same time to make each group as dissimilar from the other ones as possible.
} 
a special case of Doehlemann's boredom stemming from the excess. Kundera's active boredom also fits in with situational boredom as a more pleasant way of dealing with boredom, rather than passively waiting for something to happen. In the typology proposed by Mael and Jex, it would be a case of episodic situational boredom. Boredom as a situation-independent, pathological trait can be found in the typology proposed by Healy (who referred to it as overwhelming), Doehlemann (as existential), and Mael and Jex (as situational or chronic global). In Markowski's case, this somewhat resembles both metaphysical boredom, as well as boredom stemming from loneliness (chronic boredom does not have to be a personal tragedy in the philosophical dimension, it can be a more psychological discomfort). Hyperboredom, as well as communication and literary boredom remain their own classes. Nevertheless, hyperboredom has certain characteristics of existential boredom, in other words: chronic global boredom, after all, it is also called l'ennui moderne; however, it puts a much stronger emphasis on the pessimist nature of civilisation transformation, rather than individual problems. I have a critical attitude towards creative boredom, not because I deny the creative potential of boredom, but because I see creativity as a possible solution to the problem of curbing boredom, instead of seeing it as boredom in itself. What is more, Doehlemann himself did not in any way define the specificity of this condition, only specifying the good (that is, creative) effects only. This makes one think that different types of boredom can be overcome in a creative manner. Thus, creative boredom as a separate category lacks a rational basis in my opinion. However, I appreciate Doehlemann's recognition of the fact that boredom sometimes leads to creativity. Kundera's rebellious boredom can probably be explained by frustration and one of the symptoms of hyperboredom, as well as some elements of boredom-as-a-trait. However, vandalism or riots involving young people are not only a psychological and pedagogical issue, but also a sociological, economic and political one.

Regardless of the environmental and characteristically conditioned predispositions to be bored in a particular way, it seems that the typology suggested by Goetz and Frenzel offers a suggestion of situational dynamics of the process. I suppose that indifferent, calibrating, searching and reactant boredom can be interpreted as successive phases of boredom. In each phase it is possible to break this state (although in indifferent boredom there is no motivation to do so), but if this does not happen, over time a person can enter the next phase, and thus experience more and more powerful boredom. Even apathetic boredom can be added here at the end as a case of breakdown in a stressful situation. Reactant boredom is particularly well suited to Greenson's agitated boredom, just like 
searching boredom to a certain extent, while apathetic boredom would be tantamount to Greenson's concept by the same name. It is also a way of comprehensively solving the problem of agitation in boredom. To sum up, it is worth adding that people prone to boredom, those with high levels of boredom-as-a-trait, experience boredom more often, longer and more strongly, so they probably experience reactive or apathetic boredom more often than others. Although under particularly boredom-promoting environmental conditions, reactive boredom, and perhaps even apathetic boredom, can probably be induced in people who are generally less prone to such phenomena. Another issue is indifferent boredom, experienced in a positive mood, when it is known that boredom is commonly regarded as a negative emotion. Perhaps what the authors called indifferent boredom is not boredom at all.

\section{Instead of a summary}

Theoreticians, researchers, philosophers and artists have been the authors of numerous typologies of boredom, and the majority of arguments are in favour of two of them: two-category and five-category ones. A two-category typology of boredom divides it into a situational condition (with some agitation or apathy, depending on the manner and extent of agitation) and a dispositionally conditioned trait. The five-category typology does not stand in opposition to the two-category typology, as it operates at the level of the currently experienced state, based on the arousal and pleasure, or lack thereof. The hypothetical relationships of the five-category typology of boredom with boredom-as-a-trait were outlined above.

The variety of approaches to boredom can be to a certain extent ordered and better understood when the multiplicity of forms of boredom is seen in the context of the multiplicity of its causes (from civilisational to biochemical). Over the last dozen or so years, we have been witnessing intensive work on creating and improving questionnaires measuring various aspects of boredom. In simple terms, one could say that general or contextually specific measures of boredom-as-a-trait or boredom-as-a-state are being developed. These two divisions cross each other. Thus, we come at another four-category typology, implicitly accepted by the authors of the measurement scales and recognised by Vodanovich (2003: 569-570; Vodanovich, Watt, 2015: 3), quite similar to the one proposed by Mael and Jex (2015: 137). I am quite certain that science has not yet said the last word in this field, which brings us to the conclusion that boredom is not necessarily boring. 


\section{Bibliography}

Baratta P.L., Spence J.R. (2018), Capturing the noonday demon: development and validation of the State Boredom Inventory, European Journal of Work and Organizational Psychology, no. 27, pp. 477-492.

Barmack J.E. (1939), A definition of boredom: a reply to mr. Berman, The American Journal of Psychology, no. 52, pp. 467-471.

Baudelaire Ch. (1991), Kwiaty zła, Kraków.

Bizior-Dombrowska M. (2016), Romantyczna nuda. Wielka nostalgia za niczym, Toruń.

Cheyne J.A., Carriere J.S.A., Smilek D. (2016), Absent-mindedness: lapses of conscious awareness and everyday cognitive failures, Consciousness and Cognition, no. 15, pp. 578-592.

Csikszentmihalyi M. (1975), Beyond Boredom and Anxiety, San Francisco.

Davies A.H. (1926), Discussion on the physical and mental effects of monotony in modern industry, The British Medical Journal, no. 2, pp. 472-479.

Elpidorou A. (2018), The bored mind is a guiding mind: toward a regulatory theory of boredom, Phenomenology and the Cognitive Sciences, no. 17, pp. 455-484.

Fahlman S.A. (2008), Development and Validation of the Multidimensional State Boredom Scale, manuscript of a PhD dissertation, York University, York (Canada), http://www.todmanpsychology. org/resources/Development\%20and\%20validation\%20of\%20the\%20multidimensional\%20 state\%20boredom\%20scale\%20(diss.)\%20(Fahlman,\%202009).pdf, accessed: 1.05.2014.

Fahlman S.A., Mercer-Lynn K.B., Flora D.B., Eastwood J.D. (2013), Development and validation of the Multidimensional State Boredom Scale, Assessment, no. 20, pp. 68-85.

Farmer R., Sundberg N.D. (1986), Boredom proneness - the development and correlates of a new scale, Journal of Personality Assessment, no. 50, pp. 4-17.

Fenichel O. (1951), On the psychology of boredom, [in:] D. Rapaport (ed.), Organization and Pathology of Thought: selected sources, New York, pp. 349-361.

Flakus M., Palt Ł. (2016), Psychologicznie o nudzie - teorie i modele nudy, Stan Rzeczy. Teoria Społeczna. Europa Środkowo-Wschodnia, no. 2, pp. 119-138.

Flaubert G. (1955), Bouvard i Pécuchet, trans. W. Rogowicz, Warszawa.

Gadacz T. (2002), O umiejętności życia, Krakow.

Geiwitz P.J. (1966), Structure of boredom, Journal of Personality and Social Psychology, no. 3, pp. 592-600.

Goetz T., Frenzel A.C., Hall N.C., Nett U.E., Pekrun R., Lipnevich A.A. (2014), Types of boredom: an experience sampling approach, Motivation and Emotion, no. 38, pp. 401-419.

Goodstein E.S. (2005), Experience without Qualities: boredom and modernity, Stanford.

Greenson R.R. (1949), The psychology of apathy, The Psychoanalytic Quarterly, no. 18, pp. 290-302.

Greenson R.R. (1953), On boredom, Journal of the American Psychoanalytic Association, no. 1, pp. 7-21.

Gurycka A. (1977), Przeciw nudzie. O aktywności, Warszawa.

Healy S.D. (1984), Boredom, Self, and Culture, Cranbury.

Hill A.B., Perkins R.E. (1985), Towards a model of boredom, British Journal of Psychology, no. 76, pp. $235-240$.

Kierkegaard S. (1976), Albo-albo, trans. J. Iwaszkiewicz (vol. 1) and K. Toeplitz (vol. 2), Warszawa.

Krasicki I. (1994), Pan Podstoli, Olsztyn.

Kundera M. (2001), Tożsamość, trans. by M. Bieńczyk, Warszawa. 
Mael F., Jex M. (2015), Workplace boredom: an integrative model of traditional and contemporary approaches, Group \& Organization Management, no. 40, pp. 131-159.

Maggini C. (2005), Psychobiology of boredom, CNS Spectrums, no. 5, pp. 24-27.

Markowski M.P. (1999a), L’ennui: ułamek historii, [in:] P. Czapliński, P. Śliwiński (eds.), Nuda w kulturze, Poznań, pp. 290-316.

Markowski M.P. (1999b), Anatomia ciekawości, Krakow.

Merrifield C. (2014), Toward a model of boredom: investigating the psychophysiological, cognitive, and neural correlates of boredom, manuscript of a $\mathrm{PhD}$ dissertation, University of Waterloo, Waterloo (Canada). [retrieved on from: https://core.ac.uk/download/pdf/144147639.pdf, accessed: 20.02.2019.

Mikulas W.L., Vodanovich S.J. (1993), The essence of boredom, Psychological Record, no. 43, pp. 3-12.

Misztal B.A. (2016), The ambiguity of everyday experience: between normality and boredom, Qualitative Sociology Review, no. 12, pp. 100-119.

Montaigne, M. de (2009), Próby, trans. T. Boy-Żeleński, Warszawa.

Neu J. (1998), Boring from within: endogenous versus reactive boredom, [in:] W.F. Flack Jr., J.D. Laird (eds.), Emotions in Psychopathology. Theory and research, New York-Oxford, Inc., pp. 158-170.

Ng A.H., Liu Y., Chen J., Eastwood J. (2015), Culture and state boredom: a comparison between European Canadians and Chinese, Personality and Individual Differences, no. 75, pp. 13-18.

O’Brien W. (2014), Boredom, Analysis, no. 74, pp. 236-244.

Pekrun R., Goetz T., Daniels L.M., Stupnisky R.H., Perry R.P. (2010), Boredom in achievement settings: exploring control-value antecedents and performance outcomes of a neglected emotion, Journal of Educational Psychology, no. 102, pp. 531-549.

Plutchik R. (1980), Emotions: a psychoevolutionary synthesis, New York.

Russell B. (1970), The Conquest of happiness, London.

Russell J.A. (1980), A circumplex model of affect, Journal of Personality and Social Psychology, no. 39, pp. 1161-1178.

Sundberg N.D., Latkin C.A., Farmer R.F., Saoud J. (1991), Boredom in young adults: gender and cultural comparisons, Journal of Cross-Cultural Psychology, no. 22, pp. 209-223.

Svendsen L. (2005), A Philosophy of Boredom, London.

Szmidt J.K. (2013), Nuda jako problem pedagogiczny, Teraźniejszość - Człowiek - Edukacja, no. 16, pp. 55-69.

Tardieu E. (1904), Znudzenie. Studyum psychologiczne, trans. M. Massonius, Warszawa.

Tilburg W.A.P. van, Igou E.R. (2012), On boredom: lack of challenge and meaning as distinct boredom experiences, Motivation and Emotion, no. 36, pp. 181-194.

Todman M. (2003), Boredom and psychotic disorders: cognitive and motivational issues, Psychiatry, no. 66 , pp. 146-167.

Vodanovich S.J. (2003), Psychometric measures of boredom: a review of literature, The Journal of Psychology, no. 137, pp. 569-595.

Vodanovich S.J., Watt J.D. (1999), The relationship between time structure and boredom proneness: an investigation within two cultures, The Journal of Social Psychology, no. 139, pp. 143-152.

Vodanovich S.J., Watt J.D. (2015), Self-report measures of boredom: an updated review of the literature, The Journal of Psychology, no. 150, pp. 196-228.

Winter R. (2012), Nuda w kulturze rozrywki. Poradnik, trans. Z. Kasprzyk, Kraków.

Zuckerman M., Eysenck S.B.G., Eysenck H.J. (1978), Sensation seeking in England and America: cross-cultural, age, and sex comparisons, Journal of Consulting and Clinical Psychology, no. 46, pp. 139-149. 
